5. MacAyeal, D. R. Thermohaline circulation below the Ross Ice Shelf: A consequence of tidally induced vertical mixing and basal melting. J. Geophys. Res. 89, 597-606 (1984).

6. Jacobs, S. S., Amos, A. F. \& Bruchhausen, P. M. Ross Sea oceanography and Antarctic Bottom Water formation. Deep-Sea Res. 17, 935-962 (1970).

Jacobs, S. S., Fairbanks, R. G. \& Horibe, Y. in Oceanology of the Antarctic Continental Shelf (ed. Jacobs, S. S.) 59-85 (Antarctic Res. Ser. 43, Am. Geophys. Un., Washington DC, 1985).

8. Foldvik, A. \& Gammelsrød, T. Notes on Southern Ocean hydrography, sea-ice and bottom water formation. Palaeogeogr. Palaeoclimatol. Palaeoecol. 67, 3-17 (1988).

9. Nicholls, K. W. Temperature variability beneath Ronne Ice Shelf, Antarctica, from thermistor cables. J. Geophys. Res. 101, 1199-1210 (1996).

10. Foldvik, A., Gammelsrød, T. \& Tørresen, T. in Oceanology of the Antarctic Continental Shelf (ed. Jacobs, S. S.) 5-20 (Antarctic Res. 43, Am. Geophys. Un., Washington DC, 1985).

11. Gammelsrød, T. et al. in The Polar Oceans and their Role in Shaping the Global Environment (eds Johannesen, O. M., Muench, R. D. \& Overland, J. E.) 159-176 (Geophys. Monogr. 84, Am. Geophys. Un., Washington DC, 1994)

12. Mitchell, J. F. B., Johns, T. C., Gregory, J. M. \& Tett, S. F. B. Climate response to increasing levels of greenhouse gases and sulphate aerosols. Nature 376, 501-504 (1995).

13. Grumbine, R. W. A model of the formation of High-Salinity Shelf Water on polar continental shelves. J. Geophys. Res. 96, 22049-22062 (1991).

14. Jacobs, S. S., Hellmer, H. \& Jenkins, A. Antarctic Ice Sheet melting in the Southeast Pacific. Geophys. Res. Lett. 23, 957-960 (1996).

15. Johnson, M. R. \& Smith, A. M. Seabed topography under the southern and western Ronne Ice Shelf, derived from seismic surveys. Antarct. Sci. 9, 201-208 (1997).

16. Vaughan, D. G. et al. Map of subglacial and seabed topography 1:2000000 Filchner-Ronne-Schelfeis, Antarktis (Institut für Angewandte Geodäsie, Frankfurt am Main, Germany, 1994).

Acknowledgements. I thank all those who have helped with the fieldwork, and W. M. Connolly for analysis of model data.

Correspondence should be addressed to K.W.N. (e-mail: k.nicholls@bas.ac.uk).

\section{Laboratory simulations of sustained volcanic eruptions}

\section{H. M. Mader ${ }^{\star}$, E. E. Brodsky $\dagger$, D. Howard $\ddagger$ \\ \& B. Sturtevant $\ddagger$}

* Department of Geology, University of Bristol, Wills Memorial Building,

Queens Road, Bristol, BS8 1RJ, UK

$\dagger$ Seismological Laboratory, $¥$ Graduate Aeronautical Laboratories, California

Institute of Technology, Pasadena, California 91125, USA

Many violent eruptions are driven by rapid exsolution of dissolved volatiles within liquid magma. The accelerating two-phase mixture emerges at the vent as a sustained quasi-steady discharge lasting for periods from hours to days (refs 1,2$)$. The initial growth in discharge rate commonly observed ${ }^{2-4}$, subsequent fluctuations $s^{5,6}$ and discrete pulses and shocks ${ }^{7}$ remain largely unexplained. We have simulated volcanic conduit flows by producing sustained, quasi-steady explosions in a liquid undergoing rapid exsolution of a gas. This was done by rapidly decompressing large volumes of $\mathrm{CO}_{2}$-saturated water. The results reveal fluctuations in discharge rate that reflect heterogeneities in the twophase mixture that form spontaneously as a consequence of the size and geometry of the experimental system. An initial transient with a growing discharge rate is observed in experiments in which material is erupted from a spherical flask up a narrow neck that mimics the magma-chamber/conduit assembly of volcanic systems. The fragmentation region propagates down the neck during the initial transient until it reaches a stable position at the top of the flask, at which point a quasi-steady discharge ensues.

The experiments were carried out (Fig. 1) using a shock-tube facility at the California Institute of Technology, previously described by Mader et al. ${ }^{8}$. Until now, exsolution experiments using this apparatus have been restricted to the study of discrete, transient explosions (typical durations of a few milliseconds) using small sample volumes $(100 \mathrm{ml} \text { or less })^{8}$. Other shock-tube experiments have been similar in this respect ${ }^{8-11}$, although quasi-steady flows of short duration ( $\sim 20 \mathrm{~ms}$ ) have been generated by explosive vaporization $^{12,13}$. In the experiments reported here, much larger sample volumes, between 0.5 and $1.8 \mathrm{l}$, and two different test cells are used. The first arrangement (Fig. 1a) uses a cylindrical test cell with a constriction at the top, which has the effect of slowing down the eruption and thereby increasing its duration. Experiments in which the constriction is omitted have a shorter duration but show qualitatively the same behaviour. In the second arrangement (Fig. 1b), material is erupted from a large sphere up a narrow neck.

The problem of scale is central to understanding the laboratory eruptions. A true simulation involves reproducing the flow dynamics of a large-scale natural system within a small-scale model by matching the ratios of important forces. But we do not know which of the many force ratios within the bulk flow control the regime of these high-density two-phase flows. Similarity can be achieved on the scale of individual particles, but this will not necessarily lead to similar bulk flow behaviour, because the overall flow is dominated by particle-particle interactions. Thus, the approach taken is to replicate as many of the dynamical parameters of the system is possible, while providing a wide range of spatial scales, so that the long-range particle-particle interactions can act. Velocities and accelerations in our experiments (locally up to $20 \mathrm{~m} \mathrm{~s}^{-1}$ and $100 \mathrm{~g}$ ) are similar to those found in nature ${ }^{1,2}$. Gravitational effects $(1 \mathrm{~g})$ do not control the dynamics of flows that experience such large accelerations and are therefore not modelled. Viscous forces are also not scaled. But numerical calculations indicate that, even under conditions of explosive eruptions, diffusive bubble growth is not retarded by viscous effects unless magma viscosities exceed $10^{8} \mathrm{~Pa}$ s (refs 14, 15); this condition is not generally reached during fragmentation because magmas are not fully degassed.

The times involved in the laboratory experiments are necessarily scaled down compared to nature by the same factor as the physical dimensions, given similar velocities. This scaling applies also to the duration that may be considered to represent a sustained eruption. Typical eruption durations in the laboratory are between 1,500 and $3,000 \mathrm{~ms}$, about 100 times longer than in previous experiments ${ }^{8}$, and about 50 times the particle transit time up the neck (30-50 ms). This is similar to the ratio of eruption duration $(\sim 1 \mathrm{~d})$ and estimated particle transit times between magma chamber and vent $(\sim 1,000 s)$ in typical plinian events ${ }^{5}$. Thus, our laboratory explosions are sustained events that are similar in this respect to natural eruptions.

The physical process driving the explosions is the same as in earlier experiments and so the early behaviour is as previously reported $^{8}$; there is a single nucleation event and bubbles grow in unison. Early in its development, the experiment reaches a state typical of the inception of natural eruptions due to an unloading event. Increases of spatial and temporal scales (sample volumes up to 20 times larger and eruptions durations 100 times longer) provide the opportunity to observe in detail the subsequent flow evolution. All the flows develop pronounced heterogeneities, as shown in Figs 2 and 3. Discrete pulses of finely vesicular material form repeatedly on a scale initially related to the test-cell diameter. These pulses combine, owing to their different velocities, leading to growth in the overall pulse-length with height.

In the flask experiments (Figs 2 and 4), quasi-steady flow conditions are reached after an initial transient, which is complete by $t \approx 400 \mathrm{~ms}$ after diaphragm rupture. During the transient, the discharge rate grows (Fig. 4) and the fragmentation region propagates down the neck until it reaches a stable position at the exit from the sphere (Fig. 2). Thereafter, the flow is characterized by a virtually static foam that fills the sphere and a highly turbulent, heterogeneous and fragmented flow in the neck. This situation persists for $\sim 1,300 \mathrm{~ms}$. The average bulk discharge rate is roughly constant once the initial transient is complete, but small-scale heterogeneities within the flow lead to the formation of discrete pulses (Fig. 2).

These results have a number of important implications for our understanding of explosive volcanic eruption dynamics.

First, the spontaneous and sudden breakup into spatially and temporally highly heterogeneous flows is a result of the increase in scale of the experiments; a larger range of scales is available and the particle-particle interactions have more time and space to evolve. 
Further scaling-up to natural dimensions will tend to increase the degree of heterogeneity. In particular, heterogeneities on larger scales, relative to conduit dimensions, should be expected as even longer-range fluid interactions come into play. Thus, we can conclude that volcanic eruptions are inherently heterogeneous because of their scale.

Second, the common observation of discharge rates growing with time during the initial phase of a volcanic eruption has been previously explained in terms of steady erosion of the conduit ${ }^{2-4}$. However, this behaviour is closely replicated in our experiments using the flask arrangement, which suggests that independent of any concomitant conduit erosion, a discharge rate increase could be induced by geometrical effects associated with the magma chamber feeding a narrow conduit-a feature of explosive eruption dynamics hitherto ignored by all models of explosive volcanic eruptions $^{14-18}$.

The experimental observations can be explained by considering the pressure evolution in the sphere. After diaphragm rupture, a rarefaction wave propagates down into the sphere at the speed of sound in bubble-free water, that is, effectively instantaneously
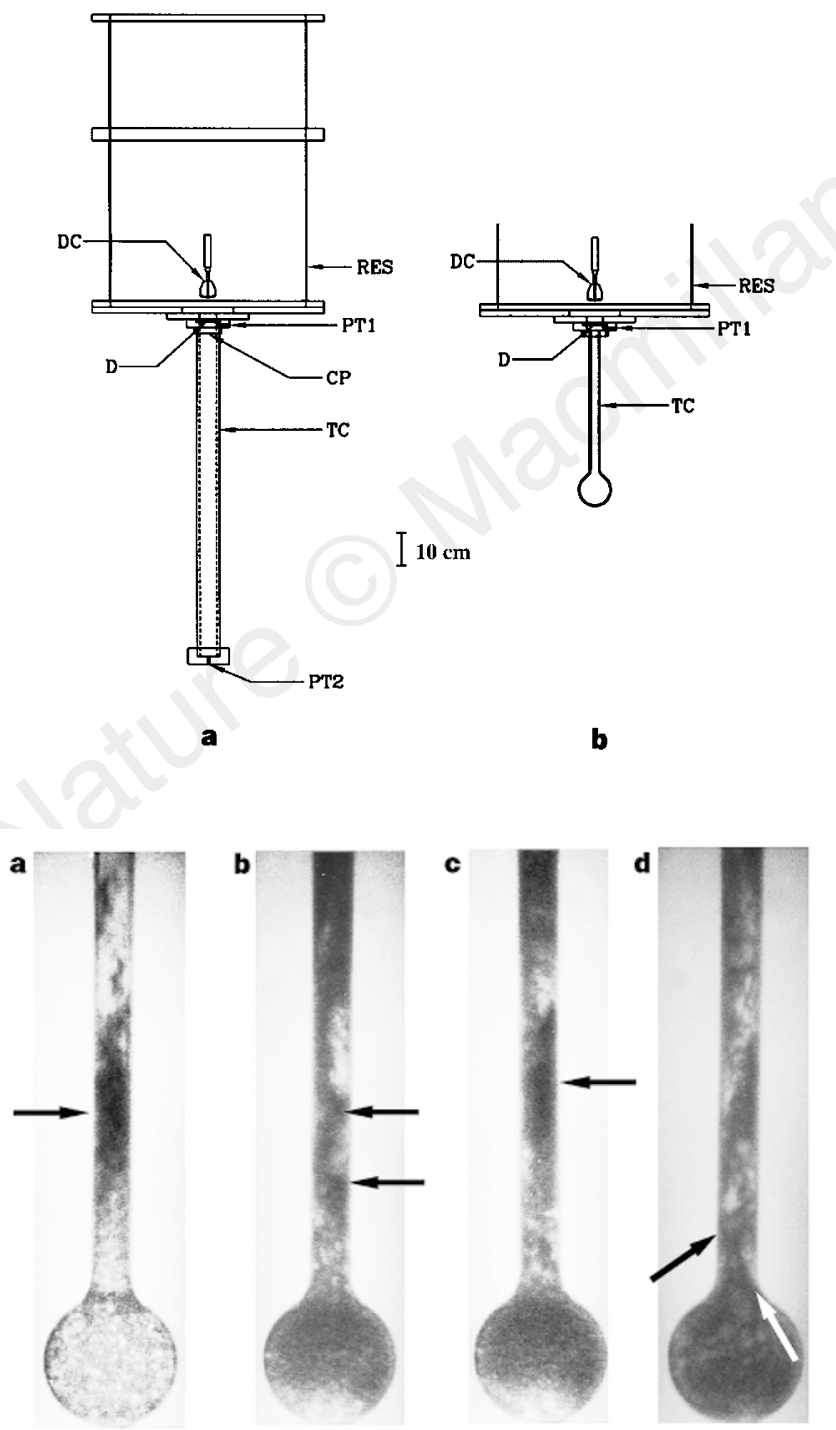

$(<0.5 \mathrm{~ms})$, and bubbles are nucleated. But bubble growth is limited by the rate of gas diffusion into the bubbles and the rate at which material can escape from the sphere, both of which are governed by the pressure in the sphere and bubbles. Quasi-steady flow conditions occur when a pressure balance is reached between gas diffusion into the bubbles and flow out of the sphere. This condition is stable until the $\mathrm{CO}_{2}$ is depleted and the eruption exhausted.

The flask arrangement is a model for eruptions in which significant bubble nucleation and growth takes place in the magma chamber. This is likely to occur in eruptions that lead to extensive evacuations of the magma chamber. In such eruptions, the discharge rate is necessarily greater than the rate of influx of magma into the chamber at depth. The unloading of the magma chamber will be progressive, rather than instantaneous as in our laboratory system. Nevertheless, a steady-state discharge requires that a similar pressure balance between diffusion into bubbles and flow out of the chamber is attained.

Third, after the initial transient, the fragmentation region remains at the entrance to the neck of the flask. This is because the colliding fluid streams here provide a source of instability within

Figure 1 Experimental apparatus. Water that has been saturated under pressure with $\mathrm{CO}_{2}$ is fed into the high-pressure pyrex test cell TC (pressure $\leqslant 1,000 \mathrm{kPa}$ ) which is separated from the low-pressure reservoir RES (pressure $\sim 4 \mathrm{kPa}$, volume $260 \mathrm{I}$ ) by an aluminium diaphragm D. Sudden decompression and supersaturation is achieved by puncturing the diagphragm with a solenoid-driven cutter DC. The supersaturation causes $\mathrm{CO}_{2}$ bubbles to nucleate and grow progressively resulting in the expanding two-phase flow which erupts into the reservoir. Pressures are measured at transducers PT1 and PT2. The flows are recorded on video and high-speed motion photography at 1,000 frames per second. a, Constricted tube arrangement. The test cell consists of a long cylindrical tube (length $100 \mathrm{~cm}$, diameter $5 \mathrm{~cm}$ ) with a metal constriction plate CP mounted at the top. The constriction is provided by circular holes of varying diameters $(2.54 \mathrm{~cm}, 1.27 \mathrm{~cm}$ and $0.64 \mathrm{~cm})$ drilled centrally in the metal plate. Filldepths of $\sim 50 \mathrm{~cm}$ and $\sim 90 \mathrm{~cm}$ (liquid volumes of between $\sim 1$ and $\sim 1.8 \mathrm{I}$ ) and pressures of 750 to $1,040 \mathrm{kPa}$ are used. b. Flask arrangement. The test cell consists of a sphere (volume $\sim 0.5 \mathrm{I}$, diameter $10 \mathrm{~cm}$ ) that grades smoothly into a long cylindrical neck (length $45 \mathrm{~cm}$, diameter $2.7 \mathrm{~cm}$ ). Fill-depths up to 2 to $10 \mathrm{~cm}$ up the neck and a pressure of $760 \mathrm{kPa}$ are used.
Figure 2 Photographs of results using the flask apparatus (Fig. 1b). The timings of important events are as follows: $t=0$, diaphragm rupture; $t=9 \mathrm{~ms}$, nucleation; $t=14 \mathrm{~ms}$, start of flow front motion; fragmentation region propagates down neck at an estimated average speed of the order of $1 \mathrm{~m} \mathrm{~s}^{-1}$, reaching base of neck at $t \approx 250 \mathrm{~ms}$; eruption is exhausted at $\sim 1,500 \mathrm{~ms}$. a, Flow at $t=49 \mathrm{~ms}$, showing a well-defined fragmentation region a height $h=8 \mathrm{~cm}$ above the neck entrance (arrowed). The fragmentation region separates the uniformly bubbled liquid below from the fragmented spray above. Flows at $t=258 \mathrm{~ms}(\mathbf{b}), t=268 \mathrm{~ms}$ (c) and $t=1,282 \mathrm{~ms}(\mathbf{d})$ have the fragmentation region at the base of the neck separating the homogeneous and virtually static foam in the sphere from the highly heterogeneous and turbulent flow in the neck. The instability at the neck entrance is caused by converging streams of liquid in the sphere, coupled with the high accelerations experienced by the individual fluid particles, leading to large-scale heterogeneities and fragmentation of the liquid into small volumes of finely bubbled (that is, dark) liquid. The finely bubbled regions have very high surface-to-volume ratios and so diffusion in these regions is rapid, resulting in higher accelerations and velocities. The fragments start to gain speed and sweep through the neck, collecting material as they go. The process of slug growth is illustrated in $\mathbf{b}$ and $\mathbf{c}$. In $\mathbf{b}$, two diffuse slugs (arrowed) of finely bubbled liquid are visible separated by a region of clear fluid. In c, the two slugs have merged to form one dense slug (arrowed). The process of the initial generation of the slugs at the neck entrance is shown in $\mathbf{d}$. Converging streams of liquid at the entrance to the neck cause oscillatory behaviour (arrowed) on the scale of the neck diameter. 

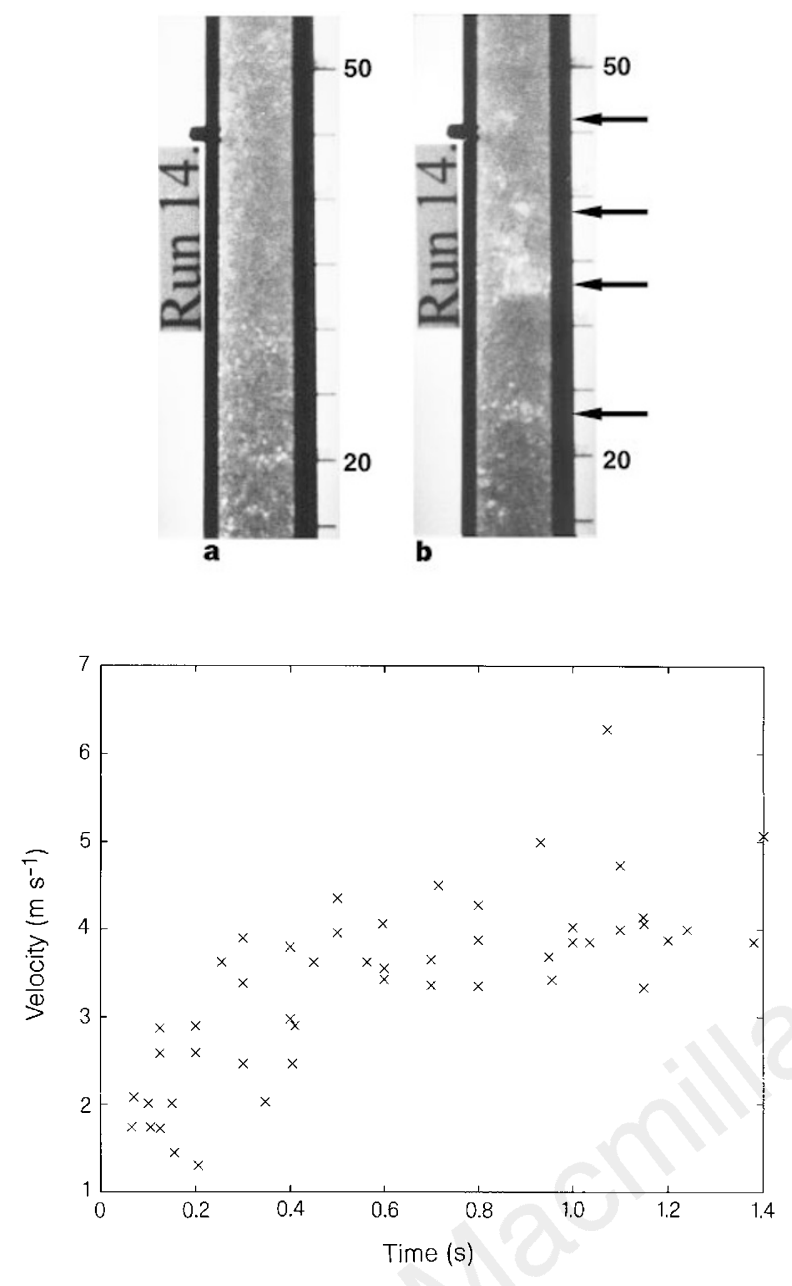

Figure 3 Photographs of results from the constricted-tube apparatus (Fig. 1a). Run conditions: fill depth $89 \mathrm{~cm}$, constriction diameter $1.27 \mathrm{~cm}$, test-cell pressure $737 \mathrm{kPa}$, reservoir pressure $4 \mathrm{kPa}$. The bubbles nucleate uniformly throughout the flow in a single event and grow in unison, resulting in the initially homogeneous flow shown in a for $t \approx 1.2 \mathrm{~s}$. A significant breakdown event then occurs leading to the flow shown in $\mathbf{b} 100 \mathrm{~ms}$ later, in which finely bubbled slugs of liquid are separated by regions of relatively bubble-free liquid (arrowed). These slugs behave in a qualitatively similar way to those seen in the flask experiments and described in Fig. 2, and are a direct results of the scale of these experiments. The eruption continues for $\sim 3,000 \mathrm{~ms}$. The numbers on the right of each panel are in centimetres.

Figure 4 Velocity at the neck entrance of the flask (Fig. 1b) as a function of time. The motion of individual blobs of fluid $1-3 \mathrm{~cm}$ from the neck entrance were tracked over $5 \mathrm{~ms}$. The graph shows that the velocity at the neck entrance increases monotonically over the first $400 \pm 100 \mathrm{~ms}$ of the run until a velocity of $\sim 4 \mathrm{~m} \mathrm{~s}^{-1}$ is reached; this remains roughly constant until the eruption is exhausted. The change from increasing velocity to constant velocity at $t \approx 400 \mathrm{~ms}$ corresponds to a break in the slope of the pressure trace measured at the top of the neck. The scatter of the data points is large because (1) the flow is turbulent and so there are real variations in velocity and (2) because the fluid blobs chosen were at variable heights and tended to change shape. The velocities measured at the neck entrance are small, and the slope over the first $400 \mathrm{~ms}$ is also small. This slope describes the eulerian acceleration, which is the change in the velocity at a point in the flow as different fluid particles move through it. It is small compared to the lagrangian acceleration, which is the acceleration experienced by a specific fluid particle as it moves past this point. The particles have negligible forward motion in the sphere and then reach a velocity of $\sim 4 \mathrm{~m} \mathrm{~s}^{-1}$ over a distance of $\sim 2 \mathrm{~cm}$ in the neck which corresponds to an average lagrangian acceleration of $\sim 200 \mathrm{~m} \mathrm{~s}^{-2}$ or $20 \mathrm{~g}$. The instantaneous accelerations are likely to be several times greater than this. the flow and also because this is where individual fluid particles experience the greatest accelerations. These conditions are at no time provided within the body of the sphere, no matter how expanded the flow becomes, and so the fragmentation region does not propagate down into it. The acceleration at the neck entrance is a function of the ratio of the typical sizes of neck and sphere. This ratio is likely to be larger in actual volcanic eruptions by at least an order of magnitude compared to our experimental apparatus. Thus, the natural accelerations will be huge as the material enters the conduit making this the most likely location for the fragmentation region.

The second and third implications (above) together provide a simple method for reaching quantitative conclusions about the flow dynamics occurring at depth during a sustained, plinian eruption. The start-up period, with growing magma discharge rate, identifies the time during which the fragmentation region is propagating down the conduit. Therefore, if the conduit length is known, then the maximum average rate of propagation of the fragmentation region can be estimated (for example, $0.6 \mathrm{~m} \mathrm{~s}^{-1}$ for $18 \mathrm{May} 1980 \mathrm{Mt}$ St Helens eruption with conduit length $\sim 7 \mathrm{~km}$ (ref. 19) and start-up period $\sim 3 \mathrm{~h}$ (ref. 5); the experimental value was $\sim 1 \mathrm{~m} \mathrm{~s}^{-1}$ - see Fig. 2 ). The position of the fragmentation region is defined as being at the top of the magma chamber for quasi-steady flow conditions, separating the static foam in the magma chamber from the turbulent and fragmented flow in the conduit.

Received 24 January; accepted 10 June 1997.

1. Walker, G. P. L. Plinian eruptions and their products. Bull. Volcanol. 44, 223-240 (1981)

2. Carey, S. \& Sigurdsson, H. The intensity of plinian eruptions. Bull. Volcanol. 51, 28-40 (1989).
3. Carey, S. \& Sigurdsson, H. Temporal variations in column height and magma discharge rate during the 79 AD eruption of Vesuvius. Bull. Geol. Soc. Am. 99, 303-314 (1987).

4. Wilson, L. Relationships between pressure, volatile content and ejecta velocity in three types of volcanic explosion. J. Volcanol. Geotherm. Res. 8, 297-313 (1980).

5. Carey, S. et al. Variations in column height and magma discharge during the May 181980 eruption of Mount St Helens. J. Volcanol. Geotherm. Res. 43, 99-112 (1990).

6. Gardner, J. E., Sigurdsson, H. \& Carey, S. N. Eruption dynamics and magma withdrawal during the plinian phase of the Bishop tuff eruptions, Long Valley caldera. J. Geophys. Res. 96, 8097-8111 (1991).

7. Sparks, R. S. J. \& Wilson, L. Explosive volcanic eruptions. 5. Observations of plume dynamics during the 1979 Soufriere eruption, St Vincent. Geophys. J. R. Astron. Soc. 69, 551-570 (1982).

8. Mader, H. M. et al. Experimental simulations of explosive degassing of magma. Nature 372, 85-88 (1994).

9. Mader, H. M. et al. Dynamics of explosive degassing of magma: Observations of fragmenting twophase flows. J. Geophys. Res. 101, 5547-5560 (1996).

10. Anilkumar, A. V., Sparks, R. S. J. \& Sturtevant, B. Geological implications and applications of high velocity two-phase flow experiments. J. Volcanol. Geotherm. Res. 56, 145-160 (1993).

11. Phillips, J. C. et al. Gum rosin-acetone system as an analogue to the degassing behaviour of hydrated magmas. Bull. Volcanol. 57, 263-268 (1995).

12. Hill, L. G. \& Sturtevant, B. in Adiabatic Waves in Liquid-Vapor Systems (eds Meier, G. E. A. \& Thompson, P. A.) 25-37 (Springer, Berlin, 1990).

13. Sugioka, I. \& Bursik, M. Explosive fragmentation of erupting magma. Nature 373, 689-692 (1995).

14. Dobran, F. Nonequilibrium flow in volcanic conduits and application ot the eruptions of Mt St Helens on May 18, 1980 and Vesuvius in AD 79. J. Volcanol. Geotherm. Res. 49, 285-311 (1992).

15. Barclay, J., Riley, D. S. \& Sparks, R. S. J. Analytical models for bubble growth during decompression of high viscosity magma. Bull. Volcanol. 57, 422-431 (1995).

16. Papale, P. \& Dobran, F. Magma flow along the volcanic conduit during the plinian and pyroclastic flow phases of the May 18, 1980, Mount St Helens eruption. J. Geophys. Res. 99, 4355-4373 (1994).

17. Sparks, R. S. J. The dynamics of bubble formation and growth in magmas: a review and analysis. J. Volcanol. Geotherm. Res. 3, 1-37 (1978).

18. Wilson, L., Sparks, R. S. J. \& Walker, G. P. L. Explosive volcanic eruptions. IV. The control of magma properties and conduit geometry on eruption column behaviour. Geophys. J. R. Astron. Soc. 63, 117148 (1980).

19. Rutherford, M. J. \& Devine, M. J. The May 18, 1980, eruption of Mount St Helens. 3. Stability and chemistry of amphibole in the magma chamber. J. Geophys. Res. 93, 11949-11959 (1988).

Acknowledgements. We thank L. Wilson for comments. E.B. was supported by a National Science Foundation graduate fellowship. Correspondence and requests for materials should be addressed to H.M.M. (e-mail: h.m.mader@bristol.
ac.uk). ac.uk). 